\title{
Second Language Writing and Bidialectalism: A Case for African American Student Writers
}

\author{
Jason DePolo ${ }^{1}$ \\ ${ }^{1}$ English Department, North Carolina A\&T State University, Greensboro, North Carolina \\ Correspondence: Jason DePolo, English Department, North Carolina A\&T State University, Greensboro, North \\ Carolina, United States. Tel: 1-336-285-3506. Email: jdepolo@ncat.edu
}

Received: July 21, 2017 Accepted: August 14, 2017 Online Published: August 16, 2017

doi: 10.5539/elt.v10n9p140 URL: http://doi.org/10.5539/elt.v10n9p140

\begin{abstract}
There has been much research conducted on second language writing. In addition, there exists a significant amount of studies conducted with African American student writers. However, the fields of Second Language Writing and Composition Studies rarely if ever dovetail in the research literature. The purpose of this article is to argue how English language learners and bidialectal (English as a second dialect) learners share similar learning experiences and how sociocultural theories of English language pedagogy can inform composition theory, specifically as it relates to African American student writers. The study of writer identity provides insights into both bilingual and bidialectal learners' authorial identity constructions and their experiences in English language learning contexts. Based on these similarities, I argue the need for composition theory to integrate sociocultural theories of second language learning and identity to better address the needs of bidialectal learners.
\end{abstract}

Keywords: writer identity, second language writing, African American student writers, sociocultural theory, bidialectal

\section{Introduction}

ESL (English as a Second Language) and Composition Studies are two distinct fields of study with an abundance of research literature. However, there also exists many similarities between the two fields that are very useful, pedagogically, specifically for the practice of teaching writing. This connection is extremely important considering the ever-increasing number of ELLs (English Language Learners) matriculating through English-speaking schools, colleges, and universities. Unfortunately, there has been little scholarship both theoretically and empirically that combine SLW (Second Language Writing) scholarship and Composition Studies (see Matsuda, 1999). This article's overarching goal is to demonstrate how research in SLW directly contributes to the field of Composition Studies. The primary hypothesis argues that theories of language learning and identity can specifically address the needs of bidialectal learners, such African American student writers.

It is relatively common knowledge that languages vary externally. When an individual can use two different languages, then the individual is considered bilingual. However, languages also vary internally. I define bidialectal as being the ability to use two varieties or dialects of a language. The specific focus for this article are African American student writers who use both SAE (Standard Academic English) and AAE (African American English). As mentioned previously, very little research has been done to demonstrate how inquiry into SLW can inform Composition Studies. The importance of this article is that it develops a strong rationale of how this research can benefit bidialectal learners, such as African American student writers and contribute to a prominent gap in the existing research literature.

\section{Method}

The framing research questions for this article are two-fold:

1) What arguments can be made to support the importation of Second Language Writing theory and research into contemporary Composition Theory?

2) How can research into sociocultural theories of identity benefit bidialectal learners, such as African American student writers? 


\section{Discussion}

Students not only construct texts, but they also construct or reproduce their identities within them (Ivanic, 1998; Ivanic \& Camps, 2001). In recent years, new research has emerged with a focus on how students reproduce or transform their identities in the texts they write. Linguistic structures within student essays have shown the mediation between their identities and the social world (Kramsch, 2000; Pavlenko \& Lantolf, 2000), providing insight into the interrelationships between learning and identity (Ibrahim, 1999; Lin, 1999). The use of English language learner research to inform composition theory for African American student writers is justified in that both second language learners and learners of English as a second dialect share similar racial experiences toward language and schooling.

\subsection{Sociocultural Theory and Identity Construction}

Albertinti (2008) makes a case for coupling the research on second language learners with those of linguistic minorities, such as bidialectal learners. Both groups are culturally and linguistically marginalized in American Society (p. 387). Albertinti continues, "language proficiency distinguishes learners of English as a second language (ESL), learners of English as a second dialect ... from other types of students discussed in this chapter" (p. 390). The same argument is made by Donahue (2009) who calls for a synchronization between second language research and mainstream composition research. Donahue (2009) mentions the longstanding tradition of scholarship on linguistically diverse students by ESL professionals long before becoming a popular subject in composition (p. 217). She argues, “ ... we find higher education writing scholarship done beyond our borders, and other comparative studies of written texts in other national contexts through contrastive, comparative, and intercultural rhetorics" (p. 223). Donahue (2009) claims the bulk of this work remains on the margins and is unknown in U.S. composition circles except for those reading ESL research. Foci, such as discourse analysis and cognitive work, staples of scholarship in international writing research contexts, can be effectively imported to illuminate composition research done in the United States (Donahue, 2009, p. 229). This suggestion seems to indicate the logic in using second language scholarship to support research done on bidialectal, linguistically diverse students (i.e. African Americans).

This relatively new field of inquiry on the reproduction and transformation of identity in student texts was traditionally studied through cognitive frameworks (Bernstein, 1971; Greenfield, 1972; Lunsford, 1979; Flower \& Hayes, 1981). However, cognitive frameworks are insufficient in accounting for the social aspects shaping and shaped by composing processes (Brodkey, 1987; Trimbur, 1987; Rose, 1988). Composition theory must consider how the social world impacts and is impacted by writer identity. The study of identity is a viable tool in unlocking the relationship of the African American student writers and their texts to socially constructed realities.

The focus on composing processes, syntactic, lexical, and rhetorical structure has been viewed through the lens of a 'computational metaphor' (Ellis, 2000). This metaphor views the mind as the sole processing and developmental agent of language learning and acquisition. However, relatively recent work sheds light on the previously ignored roles social dimensions play on the development of literacy through the application of sociocultural theory. Sociocultural theory, it is important to note, is not solely based on social aspects as it also accounts for psycholinguistic activity (Ellis, 2000, p. 197).

Sociocultural theory is grounded in the work of L.S. Vygotsky (1986) who argued for the interrelatedness of social and cognitive aspects of language development. The human mind be a system that is culturally shaped (Lantolf, 2000, p. 2). Therefore, the aim of sociocultural research (Wertsch, del Rio, and Alvarez, 1995) is to comprehend the relationships between psychological functioning and cultural/institutional setting.

The traditional dichotomy between cognitive and social dimensions of literacy has narrowed the understanding between how the mind and the social world interact. The computation metaphor of language learning recognizes language can be studied in social context; however, the metaphor posits that the use of language itself through signs and symbols exists only in reference to something outside of language. Sociocultural theorists, such as Kramsch (2000), recognize that "for Vygotsky, psycholinguistic processes are the reconstruction in the mind of the individual of the mediated social interactions that this individual has experience on the social plane" (p. 133). Therefore, the individual and the outside world are not two separate entities merely interacting; rather, they develop relative to one another.

A field of inquiry has emerged that seeks to illuminate the "writer" of texts with a focus on identity and voice. The study of discoursal identity construction in students' texts has provided insights into the interaction of the writer in relation to the social worlds he or she is writing in and for and what this suggests about the psychological formulation and projection of self in written texts. Ivanic and Camps (2001) and Ivanic (1998) 
demonstrate that identity is constructed in written texts just as it is in aspects of speech. "Writing always conveys a representation of the self of the writer" (Ivanic \& Camps, 2001, p. 3). Therefore, writing pedagogy that attempts to unpack the personal and cultural identities found in student texts can raise a critical awareness and help students negotiate their exposure to different discourse mediums.

"The most fundamental concept of sociocultural theory is that the human mind is mediated" (Lantolf, 2000, p. 1). This mediation occurs between the individual and the physical world using what Vygotsky called physical and symbolic artifacts which can change as they are handed down from generation to generation (p. 1). The primary focus of a sociocultural theory of discourse is the use of language as a symbolic artifact. Language is a tool, which mediates our relationship with the world and others. Physical artifacts, such as writing implements and computers, have also evolved and impact individuals' relations with the world. One need only consider the communicative functions of email and how it has drastically altered how people communicate with one another. The availability of artifacts is shaped and bound by the culture from which they originate; therefore, individuals have mediational means made available to them from their cultures and are regulated by them to varying degrees.

\subsection{Writing and Authorial Identity}

Activities, such as writing, are mediated using signs called sign operations (Kramsch, 2000), and these sign operations regulate behavior. This identifies with Vygotsky's notion that individuals are not merely regulated by external stimuli but themselves create signs which they can act upon. African American students bring with them a plethora of signs that were created by their environments: how they write, how they speak, even how they dress. However, through the exposure to academic discourses, they gain the ability to create signs to varying degrees to meet their communicative needs, and the creation of meaning in the texts they create occurs by combining and recombining already existing signs (Kramsch, 2000). These signs can then be decoded by the reader in various ways, which provides the basis for much of the sociocultural investigations into identity.

Kramsch (2000) refers to the work of Peirce who, like Vygotsky, suggested the indicative function of signs but went beyond to explore the symbolic functions of icon and symbol (p. 135). The iconic function of signs extends beyond reference/meaning to the ability of signs to convey "certain values, attitudes, and beliefs" or "as reproducing or subverting certain conventionalized rules of use" (Kramsch, 2000, p. 136). Since African American students use signs as tools in a particular writing situation, they will eventually impact how they view what they are talking about. The signs move from a role of expressing meaning to a role of constructing students' realities, and consequently, their identities. Kramsch (2000) observed a class where a teacher had students respond to a written summary by summarizing it. Initially, the students remained on the level of the story. Through instruction pointing out students' use of signs (word selection, rhetorical strategies, and positioning), the students began to see the difference between complying with the referential meaning of the text and the interpretative abilities they are capable of through the use of their own signs. The students begin to construct their own authorial and discursive identities, transitioning old sign operations into the newly expected ones. The study of identity here has a very significant and practical purpose, especially for African American students whose home discourses may differ drastically from those expected in the academy.

Pavlenko and Lantolf (2000), who investigated first-person narratives documenting second language learners' experiences with learning English, conducted another illuminating study into the discursive transformation and reconstruction of self. They argue that first-person accounts in the form of personal narratives offer much richer insights than "traditional" third-person distal observation (p. 157).

Contrary to the traditional subordinating of the first-person narrative, Pavlenko and Lantolf (2000) study the culturally significant narratives of several American and French authors of Eastern European origin. Like the Kramsch (2000) study, they find that second language writers often find themselves in transition between the signs they are equipped to use and the new signs they must acquire to successfully write and speak English. Two examples of this need to reidentify oneself culturally and linguistically occur in passages by Yakobson and Hoffman. Yakobson suggests the cultural need for reidentification, "My 'Americanization' took place at all levels of my existence; in one sweep I had lost not only my family and my familiar surroundings, but also my ethnic, cultural, and class identity" (as cited in Pavlenko \& Lantolf, 2000, p. 164). Hoffman offers a more linguistic claim, "I wait for that spontaneous flow of inner language which used to be my nighttime talk with myself... In English, the words have not penetrated those layers of my psyche from which a private connection could proceed" (as cited in Pavlenko \& Lantolf, 2000, p. 165). These two examples illustrate the lack of mediational means the two authors had in making sense of their experiences. Yakobson and Hoffman's social and private speech were unable to mediate their relationship to the world and their inner mental order (p. 165). 
Their identities were constructed in a time and place with very different conventions than the current conventions they were encountering, which can be said for many African American students entering the academy. The African American scholar Jacqueline Jones Royster states:

... I've accepted the idea that what I call my "home place" is a cultural community that exists still quite significantly beyond the confines of a well-insulated community that we call the "mainstream," and that between this world and the one that I call home, systems of insulation impede the vision and narrow the ability to recognize human potential ... (p. 616).

Of course, both Yakobson and Hoffman eventually attain the signs of the new language and can establish themselves as successful writers with the result being a restructuring of their identities. However, according to Pavlenko and Lantolf (2000), success or failure depends directly on agency and intentionality. Agency and intentionality directly relate to the writer's identity and the willingness to adopt the language of the majority. These factors play an important role in determining the degree to which African American students appropriate or resist the academic discourses they encounter.

The restructuring and transformation of cultural and linguistic identity is a complex and frustrating process. Pavlenko and Lantolf (2000) suggest a writer must choose to do this willingly; however, external factors such as the position of the writer in the native discourse and the power relations between discourses also contribute to success and failure (p. 171). As in the case of Kramsch (2000), the study of identity in writing provides valuable insight into the internal processes of second language and bidialectal student writers and the external manifestations of identity in text.

Another productive focus on identity, stemming from what Pavlenko and Lantolf (2000) called agency and intentionality, is the student's willingness to reproduce or transform identity in the classroom. Traditionally, with the theories of Saussaure (2006) and Chomsky (2006), linguistics has not been concerned with the student's shifts of attention or interest in the acquisition of the target language. Bourdieu (1991) charges traditional linguistics with "converting the immanent laws of legitimate discourse into universal norms of correct linguistic practice, [which] sidesteps the question of economic and social conditions of the acquisition of the legitimate competence and of constitution of the market in which this definition of the legitimate and the illegitimate is established and imposed" (p. 44). Students bring with them a cultural capital (Bourdieu, 1991), which consists of various skills, attitudes, language uses, and intentions, collectively called habitus, that are a product of their socialization within their home communities and cultures. This inherited habitus constructs their home identities and causes conflict when faced with the appropriation of new, academic identities. Students from disadvantaged groups then do not have the cultural capital that is compatible with the school expectations. Often the result is for the student to either resist or attempt to conform their identities to these expectations. This view of Bourdieu's has been challenged as being overly deterministic.

For example, Lin's (1999) study of four classrooms situated in different socioeconomic contexts of Hong Kong reveals the possibility for creative, discursive agency (Collins, 1993). She, like Collins, recognizes the determinism inherent in Bourdieu's view and develops a study to determine that students are not merely "puppets of larger social forces and structures" (pp. 395-396). Lin (1999) claims that Hong Kong's symbolic market (Bourdieu, 1991) requires students to possess resources, such as linguistic skills and cultural knowledge, if they are to gain access to valuable social and educational opportunities (pp. 396-397). The students as agents are caught in a dilemma because of the perceived futility in changing the social market.

In two of the classrooms Lin (1999) studied, the students came from disadvantaged socioeconomic backgrounds. The agency and intentionality, however, of the students in each classroom differed vastly. In one classroom, the students' attitudes are negative toward learning English because they lacked interest, competence, and confidence in learning the target language. Their habitus was such that they appeared to have convinced themselves they would never master English and so protested the curriculum. They would talk in class, were inattentive, to lessons, and spoke loudly in their mother tongue. Their teacher, who due to school policy was only allowed to teach in English, could not establish a more personal relationship with her students.

In contrast, a second classroom of students also brought with them a habitus ill-equipped with the right attitudes and agency for learning English, but the teacher strategically used L1 to help her students achieve a sense of confidence and a personal relationship with her. With the help of the teacher's creativity and the fostered personal relationships, she could instill the confidence necessary for her students to develop English skills. Lin (1999) concludes, after studying all four classrooms, that it did not matter whether the teacher used the L1 or L2 but how the teacher used either language to bring about creative, discursive agency within the students. It was this connection that allowed a transformation of the students' habitus and a restructuring of their intentionality 
toward learning English. These findings clearly establish that lack of success for second language learners is not pre-determined. The same can be said for African American learners as evidenced by an array of studies (Mehan, Hubbard, \& Villanueva, 1994; O'Connor, 1997) that demonstrate the reflexive relationships between agency and social constraints. Ibrahim (1999) similarly found that the second language classroom is not without "its politics and pedagogy of desire and investment" (p. 3).

Ibrahim's (1999) study reveals a very different perspective in relation to the transformation of identity. Studying a group of French-speaking immigrant and refugee students from continental Africa, Ibrahim (1999) finds them adopting the identity and language of African Americans, a politically and racially marginalized group:

As an identity configuration, becoming African American is deployed to talk about the subject-formation project [italics are the author's] (i.e., the process and the space within which subjectivity is formed) that is produced in and simultaneously produced by the process of language learning, namely BESL [Black English as a Second Language]. Put more concretely, becoming Black meant learning BESL ... (p. 350)

This study is important in that it reveals why students in a social space desire to take on a new identity and why they invest in the language they are attempting to acquire. The African youths seek to fit racially into a society that demands them to fit somewhere: "To fit somewhere signifies choosing or becoming aware of one's own being, which is partially reflected in one's language practice" (p. 353). The agency the students possess to choose is constrained by the representation of "Blackness" in Euro-American society, and so they develop interests in the cultural practices of African Americans.

Like Lin's (1999) study, the second language held symbolic capital (Bourdieu, 1991) that provides opportunities for material capital, such as jobs and resources. The question remains, however, as to why the African students would choose instead to identify with a politically and racially marginalized group. The answer, Ibrahim (1999) proposes is that the African students found themselves unable to identify with the dominant group; therefore, "Black popular culture emerged as an alternative site not only for identification but also for language learning" (p. 361). The confidence and agency for learning BESL is there. The African students find the symbolic capital of identifying with African American culture familiar in that the culture of African Americans mirrors the many problems they themselves face, and it instills in them a very deliberate position counter to authority. The study of identity here foregrounds the concerns of legitimizing the "illegitimate" and valuing the identities the marginalized students not only bring with them but those that the students may socially identify with and develop. Also, it emphasizes the need for conscious study regarding the social relations of language and power.

\subsection{Hegemony and Discourse}

A major focus in sociocultural research on identity has been on the discourses and identities of dominant groups (e.g., college and university curriculums) and how they often conflict with those discourses and identities of minority groups. As discussed above, students bring to classrooms a multiplicity of identities constructed in their home cultures and environments. The dominant discourses of academia are often found problematic for these students because there exists no conscious effort on the part of the majority to acknowledge their identities, which would enable an easier transition for these students to meet the expectations of higher education. Cummins (1994) suggests it is a problem for ethnocultural groups to demand the dominant groups to intervene and support "identity maintenance" but is unproblematic for the dominant groups to continue patterns of devaluation of these identities. Therefore, the perpetuation of unacknowledged identities in the academy allows for the continued conflict, and consequent academic struggle, between student identities and those supported by colleges and universities. Cummins (1994) argues that this conflict becomes an issue of power:

I want to argue that discussions of bilingual education for minority students or multicultural education programs in schools cannot be divorced from issues of power any more than the construction of identity can be divorced from our personal and group histories. (p. 146).

As a result, minority students often feel their ethnolinguistic identities are being challenged, and this dramatically impacts their attitudes toward language learning. Kells's (2002) study of Mexican-American bilingual college writers reveals that "implicit language ideologies, common misconceptions about bidialectalism/bilingualism, and the classroom attitudinal domain subvert the success of ethnolinguistic minority students" (p. 5). Very few, if any, university curriculums are designed to incorporate students' ethnolinguistic identities.

The prevailing attitude in higher education is that minority students suffer from a deficit and so are labeled "skills deficient." The deficit is often considered a product of L1 interference with the target language; however, Kells's (2002) study reveals the possibility of extralinguistic roots to this problem. She contends that despite the 
phonological, syntactic, and morphological errors in Mexican-bilingual's writing, errors which are also found in native speaker's texts, the true problem may rest in students' language attitudes. Students' language attitudes exhibit, borrowing the term from Labov (1972), "linguistic insecurity":

Linguistic insecurity or ambivalence among members of subordinate social groups is frequently reflected in negative self-perceptions and language attitudes; members of these social groups display a high regard for the language varieties that signal the elite class and concomitant low regard for their own linguistic varieties. (p. 11).

The practice of devaluing mother tongues impairs the minority learner's sense of self, negatively impacting the student's development and classroom performance. The Tex Mex speaking students in Kells's study (2002) revealed they believe Tex Mex a corrupt form of English, which further strengthened their attitudes toward Standard American English as a superior language. This attitude, as reinforced by the ethnocentric approaches to teaching composition, reflected the illegitimacy of the Mexican bidialectal/bilingual learners causing feelings of insecurity that directly impacted their academic performance. Learning English ways of writing for minority learners is much more than learning the forms and structures of academic texts but also entails the process of adopting the sociocultural views of Western society.

The sociocultural conflict inherent in adopting these views is underscored in the English composition experiences of Fan Shen (1998), a Chinese immigrant and former student at the University of Nebraska-Lincoln. Shen, coming from a Confucian-oriented cultural background, was instructed never to project his own views into a written composition. English composition, however, required him to adopt a Western view of individualism, which would have labeled him anti-Communist or boastful in his native country (p. 124). He was forced to abandon the tenements of collectivism for individualism, and the battle between "wresting" identities ensued as he struggled to create an "English Self."

Therefore, the challenge for Shen was to meet the expectations required by the English Self without completely losing the identity associated with his cultural Self. One could argue that the cultural capital Shen inherited from China better equipped him with the transition than the Mexican students in Kells's (2002) study, who illegitimized their cultural Selves. Shen could recognize not only the obvious cultural differences but was able to relate them to the logical system of English composition. For him, it "added a new dimension to me and to my view of the world", while enabling him to "imagine myself slipping into a new skin" (p. 132). This ability to eventually balance both identities is something the Mexican students were unable to manage. Shen (1998) remarks on the same pedagogical practices the Kells's (2002) study illuminates:

Composition teachers [need] not be afraid to give foreign students English "cheese", but to make sure to hand it out slowly, sympathetically, and fully realizing that it tastes very peculiar in the mouths of those used to a very different cuisine. (p. 133).

The power relationship between the majority and minority discourses is one of the subversion of the latter. The success of minority learners depends on valuing minority discourses to allow the transition to meeting the expectations of the academy and the development of an authorial identity in written texts.

Starfield's (2002) study reveals the correlation between the development of authorial identity and student success. The study uncovers the inequitable relations of power in post-Apartheid South Africa as evidenced in the texts of two black South African students, Philip and Sipho. Both students respond to the same essay prompt; however, Philip's essay receives a high mark and Sipho's a low mark. Aligning writing once again with Bourdieu's (1991) notion of symbolic and cultural capital, the success of Philip was a result of the cultural capital he brought with him to the classroom and Sipho's failure a result of the lack of it. "Philip understood that successful academic writing inserts itself within a textual or intertextual universe and with this recognition come power and authority" (Starfield, 2002, p. 128). By recognizing the texts and authors that inhabited the "textual world" of the assignment, he could successfully situate himself among them. His essay, however, demonstrated no use of integral (author stated in citing sentence) or non-integral (author in parenthesis and use of superscript numbers) citations (Hyland, 2000); however, he still, though incorrectly, integrated the ideas of other authors. The marker gave him a high mark because he could reflect an authorial identity that represents his place in the "textual world" of the text. Philip consistently used the first person plural pronoun "we", which positioned him in a position of confidence and authority so rarely seen in students' academic writing.

Sipho, on the other hand, failed to achieve an understanding of the assignment by not answering the prompt as well as failing to refer to any of the authors he used in the text of the essay. Sipho, whose cultural capital did not afford him the understanding of how to operate within "textual worlds", further failed to develop any authorial position. The marker perceived this as plagiarism and so deducted a full $10 \%$ of his grade on this account. One could easily argue that Sipho was set up to fail from the beginning due to the inherent difficulty of the prompt. 
He fails to even copy it accurately at the top of his essay. Furthermore, the claims made by Sipho in the essay that could be attributed to his own words demonstrate the time he spent "hiding himself in the words of others" (p. 137). Because of his lack of confidence with the prompt, Sipho neglects to use any first-person pronouns, opting instead to use generic forms, such as "one." His lack of endowment with the appropriate cultural capital led the marker to label him a plagiarizer.

Ivanic (1998) views plagiarism as the means by which student writers perceive they can create their discoursal selves or achieve membership in academic discourse communities. Fairclough (1992) calls "interdiscursivity", drawing on abstract discourse types as students create new text. Sipho's view of using the ideas and language of others can be blamed on the Enlightenment concept of texts as commercial products (Scollon, 1995). The utilitarian discourse system of intertextuality distributes power and privilege to writers like Philip, who can inhabit the "textual world" of academe. Because Sipho "uses" intertextuality in a less constitutive way by hiding his own authorial presence in the text, he is doomed to fail. It becomes an issue of authority and invisibility.

Hyland (2002) has explored the positive regard given to student writers who project an authority-driven identity into their texts by displaying confidence and commitment to their ideas. However, for the majority of second-language or minority learners this is a problem as the selective use of pronouns in their text reveal. The problem is twofold. On the one hand, Belcher and Braine (1995) suggest that "although undergraduates are not expected to enter a disciplinary community, they are assessed on their ability to engage in its special discourses" (as cited in Hyland, 2002, p. 1094) as the Starfield study clearly demonstrates. On the other hand, student-writing textbooks clearly demonstrate the preferred cultural practice of what Geertz (1988) calls "author-evacuated" prose. Students are deterred from using first-person pronouns and are directed toward using the more objective third-person even though a number of scholarly texts use the first-person to demonstrate authorial responsibility for research choices (Hyland, 2002, p. 1102). The Hong Kong undergraduate students in Hyland's (2002) study exhibit no problem in using the first person to describe their research choices but exhibit a considerable avoidance of using the first person to make claims and show responsibility for those claims.

"Clearly the writer invests most by using an authorial reference for this purpose and is also most vulnerable to criticism" (Hyland, 2002, p. 1104). The students use references, such as "the experiment shows" and "the most important finding was" in place of "my experiment shows" and "my most important finding was." Clearly, the degree to which second language and minority learners feel vulnerable about the ideas they present affects their overall willingness to take direct authorial responsibility for the research they are doing. Some students, however, chose to use the first-person plural "we", as Philip does, because it created a comfortable distance and much less strong degree of authorial responsibility (Hyland, 2002, p. 1108). The avoidance of authorial responsibility does not necessarily constitute a lack of the writer's own ideas; rather, it is rooted in the deeper cultural identities the student is confident using, an obviously important consideration that was overlooked in the essay of Sipho discussed above.

Sipho's essay stands as an excellent example of what Bourdieu and Passeron (1994) call the rhetoric of despair. Due to his poor understanding of the academic discourses he was expected to reproduce, Sipho seeks to "reproduce this discourse in a way which recalls the simplifications, corruptions and logical re-workings that linguists encounter in 'creolized' languages" (Bourdieu \& Passeron, 1994, p. 4). The 'linguistic misunderstanding' evident in Sipho's essay reveals the attempt of unskilled decoding of the professional message. The position of teacher as expert and student as expected conformist leads to this linguistic misunderstanding and the "game of fictive communication" (p. 12). The academic world often casts them in a position where they feel unworthy. Therefore, a student will often not interrupt a lesson that they do not understand "because the part of them that obeys the logic of the situation reminds them that if they do not understand, then they would not be present" (p. 17). Cadman (1997) found that despite all the instruction offered to second language learners concerning the conventions and practices of English academic writing, they still refer negatively to these challenges.

After eliciting the personal interpretations of their learning experiences, Cadman's (1997) research students reveal "the perception that they themselves are lost, feeling directionless in approaching their writing tasks, thus unconsciously highlighting that for them there is a direct relationship between identity and language performance" (pp. 8-9). The student does not feel that the problem is a lack of content knowledge but something missing within her (p. 9). The value of these revelations for Cadman was in the development of a pedagogical approach that addressed filling this void. Cadman (1997) suggests a pedagogy that reflexively uses personal identity as a basis for English identity. She encourages the use of the first-person pronoun "I" in earlier drafts to generate content and authorial responsibility. If the writing should require the more academic use of the impersonal, then it is no great leap to achieve this through instruction on impersonal language structures. The 
personal writing can then be adapted to meet the impersonal discourse convention without losing the author-generated ideas of the student. The authorial presence and confidence of the student increases as she used "personal language to chart her main contentions about her data...[and] was able to experiment with different linguistic expressions of a slowly modifying communicative purpose" (Cadman, 1997, p. 11).

\section{Conclusion}

The pedagogical value of research on identity is of extreme relevance to the success of students, particularly as it applies to African American students who share many of the same cultural and academic experiences as second language learners. Composition theory needs to further explore these relationships with a research agenda attentive to how sociocultural theory can inform writing pedagogy.

This article's overarching goal is to demonstrate how research in SLW directly contributes to the field of Composition Studies. Theories of language learning and identity can specifically address the needs of bidialectal learners, such African American student writers. However, more empirical research needs to be done in both the areas of Second Language Writing and Composition Studies to substantiate these claims and facilitate sound pedagogical practices for classroom application.

\section{References}

Albertinti, J. (2008). Teaching of writing and diversity: Access, identity, and achievement. In C. Bazerman (Ed.), Handbook of research on writing: History, society, school, individual, text (pp. 387-397). New York: Lawrence Erlbaum Associates.

Belcher, D., \& Braine, G. (Eds.). (1995). Academic writing in a second language. Norwood, NJ: Ablex.

Bernstein, B. (1971). Classes, codes, and control. New York: Routledge. https://doi.org/10.4324/9780203014035

Bourdieu, P. (1991). Language and symbolic power. Cambridge, MA: Harvard University Press.

Bourdieu, P., \& Passeron, J.C. (1994). Introduction: language and relationship to language in the teaching situation. In P. Bourdieu, J. C. Passeron, \& M. de Saint Martin (Eds.), Academic discourse (pp. 1-34). Stanford, CA: Stanford University Press.

Brodkey, L. (1987). Writing ethnographic narratives. Written Communication, 4(1), 25-50. https://doi.org/10.1177/0741088387004001002

Cadman, K. (1997). Thesis writing for international students: A question of identity? English for Specific Purposes, 16(1), 3-14. https://doi.org/10.1016/S0889-4906(96)00029-4

Chomsky, N. (2006). Language and mind (3rd ed.). Cambridge: Cambridge University Press. https://doi.org/10.1017/CBO9780511791222

Collins, J. (1993). Determination and contradiction: An appreciation and critique of the work of Pierre Bourdieu on language and education. In C. Calhoun, E. LiPuma, \& M. Postone (Eds.), Bourdieu: Critical perspectives (pp. 116-138). Cambridge: Polity Press.

Cummins, J. (1994). Lies we live by: National identity and social justice. International Journal of Society and Language, 110, 145-154.

Donahue, C. (2009). "Internationalization" and composition studies: Reorienting the discourse. College Composition and Communication, 61(2), 212-243.

Ellis, R. (2000). Task-based research and language pedagogy. Language Teaching Research, 4(3), 193-220. https://doi.org/10.1177/136216880000400302

Fairclough, N. (1992). Discourse and social change. Cambridge: Polity Press. https://doi.org/10.1177/0957926592003002004

Flower, L., \& Hayes, J. R. (1981). A cognitive process theory of writing. College Composition and Communication, 32(4), 365-387. https://doi.org/10.2307/356600

Geertz, C. (1988). Words and lives: The anthropologist as author. Palo Alto, CA: Stanford University Press.

Greenfield, P. (1972). Oral or written language: The consequences for cognitive development in Africa, U.S., and England. Language and Speech, 15(2), 169-178. https://doi.org/10.1177/002383097201500207

Hyland, K. (2000). Disciplinary discourses: Social interactions in academic writing. Essex, England: Pearson Education Ltd.

Hyland, K. (2002). Authority and invisibility: Authorial identity in academic writing. Journal of Pragmatics, 34, 
1091-1112. https://doi.org/10.1016/S0378-2166(02)00035-8

Ibrahim, A. M. (1999). Becoming black: Rap and hip-hop, race, gender, identity, and the politics of ESL learning. TESOL Quarterly, 33(3), 349-369. https://doi.org/10.2307/3587669

Ivanic, R. (1998). Writing and identity: The discoursal construction of identity in academic writing. Amsterdam: John Benjamins. https://doi.org/10.1075/swll.5

Ivanic, R., \& Camps, D. (2001). I am how I sound: Voice as self-representation in L2 writing. Journal of Second Language Writing, 10, 3-33. https://doi.org/10.1016/S1060-3743(01)00034-0

Kells, M. H. (2002). Linguistic contact zones in the college writing classroom: An examination of ethnolinguistic identity and language attitudes. Written Communication, 19(1), 5-43. https://doi.org/10.1177/074108830201900102

Kramsch, C. (2000). Social discursive constructions of self in L2 learning. In J.P. Lantolf (Ed.), Sociocultural theory and second language learning (pp. 133-153). Oxford: Oxford University Press.

Lantolf, J.P. (2000). Introducing sociocultural theory. In J. P. Lantolf (Ed.), Sociocultural theory and second language learning (pp. 1-26). Oxford: Oxford University Press.

Lin, A.M.Y. (1999). Doing-English-lessons in the reproduction or transformation of social worlds? TESOL Quarterly, 33(3), 393-412. https://doi.org/10.2307/3587671

Lunsford, A.A. (1979). Cognitive development and the basic writer. College English, 41(1), 449-459. https://doi.org/10.2307/376358

Mehan, H., Hubbard, L., \& Villanueva, I. (1994). Forming academic identities: Accommodation without assimilation among involuntary minorities. Anthropology and Education Quarterly, 25(2), 91-117. https://doi.org/10.1525/aeq.1994.25.2.05x0904t

Matsuda, P. K. (1999). Composition Studies and ESL writing: A Disciplinary Division of Labor. College Composition and Communication, 50(4), 699-721. https://doi.org/10.2307/358488

O'Connor, C. (1997). Dispositions toward (collective) struggle and educational resilience in the inner city: A case analysis of six African-American high school students. American Educational Research Journal, 34(4), 593-629. https://doi.org/10.3102/00028312034004593

Pavlenko, A., \& Lantolf, J.P. (2000). Second language learning as participation and the (re)construction of selves. In J.P. Lantolf (Ed.), Sociocultural theory and second language learning (pp. 155-177). Oxford: Oxford University Press.

Rose, M. (1988). Narrowing the mind and page: Remedial writers and cognitive reductionism. College Composition and Communication, 39(3), 267-302. https://doi.org/10.2307/357468

Royster, J. J. (2003). When the first voice you hear is not your own. In V. Villanueva (Ed.), Cross-talk in comp theory: A reader (pp. 611-622). Urbana, IL: National Council of Teachers of English.

Saussure, F. (2006). Writings in general linguistics (S. Bouquet \& R. Engler, Trans.). Oxford: Oxford University Press.

Scollon, R. (1995). Plagiarism and ideology: Identity in intercultural discourse. Language and Society, 24, 1-28. https://doi.org/10.1017/s0047404500018388

Shen, F. (1998). The classroom and the wider culture: Identity as a key to learning English composition. In V. Zamel, \& R. Spack (Eds.), Negotiating academic literacies (pp. 123-133). Mahwah, NJ: Lawrence Erlbaum Associates.

Starfield, S. (2002). "I'm a second-language speaker": Negotiating writer identity and authority in Sociology One. Journal of Second Language Writing, 11, 177-190. https://doi.org/10.1207/s15327701jlie0102_02

Trimbur, J. (1987). Beyond cognition: The voices in inner speech. Rhetoric Review, 5(2), 211-221. https://doi.org/10.1080/07350198709359146

Vygotsky, L. (1986). Thought and language (A. Kozulin, Tran.). Cambridge, MA: The MIT Press.

Wertsch, J. V., del Rio, P., \& Alvarez, A. (Eds.). (1995). Sociocultural studies of mind. Cambridge: Cambridge University Press. https://doi.org/10.1017/CBO9781139174299 


\section{Copyrights}

Copyright for this article is retained by the author(s), with first publication rights granted to the journal.

This is an open-access article distributed under the terms and conditions of the Creative Commons Attribution license (http://creativecommons.org/licenses/by/4.0/). 